\title{
Die Alchemie der Luft
}

\section{Erhard Taverna}

Dr. med., Mitglied der Redaktion

Eine Unterkieferkopie des Homo Heidelbergensis liegt im Kurpfälzischen Museum. Für die Ernährung dieses Urahnen des Neandertalers sorgte zuverlässig die üppige Fauna des Pleistozäns. Doch seither haben sich die Nachfahren auf über 7,3 Milliarden vermehrt, um etwa 80 Millionen zusätzlich allein im letzten Jahr. Es war 1898, als der Präsident der British Academy of Sciences grosse Hungersnöte für die 1930er Jahre ankündete. Dies für den Fall, dass die ausgehenden Reserven an stickstoffhaltigem Mineraldünger wie Guano und Salpeter nicht bald ersetzt würden.

Wir atmen unablässig Stickstoff, fast 80\% der Atmosphäre bestehen daraus, doch sind wir völlig von Pflanzen abhängig, die das Element in gebundener Form oder vermittels Wurzelbakterien direkt aus der Luft aufnehmen können. Das Apothekermuseum im Schloss Heidelberg zeigt eindrücklich, wie lange es dauerte, bis die Bausteine der Materie erkannt wurden. Eine wichtige Übergangsfigur von der Alchemie zur modernen Chemie war der Mediziner und Chemiater Georg Ernst Stahl, der trotz seiner falschen Phlogistontheorie die richtigen Fragen zum Stoffwechsel der Materie stellte. Fragen, die Scheele und Lavoisier zum Ziel führten.

Zur ehemaligen Villa von Carl Bosch (1874-1940) führt oberhalb der Schlossruine eine Strasse am Hang des Odenwaldes. Ein Teil des Wohnsitzes wurde in ein Technikmuseum umgewandelt, das dem Leben und Wirken des Nobelpreisträgers gewidmet ist. Sein Schicksal ist eng verbunden mit dem seines Mitarbeiters Fritz Haber (1868-1934), der für die katalytische Synthese von Ammoniak aus dessen Elementen Stickstoff und Wasserstoff 1919 mit dem Nobelpreis ausgezeichnet wurde. Carl Bosch war der geniale Ingenieur, der die geeigneten Maschinen entwickelte, die schon 1911 über zwei Tonnen Ammoniak $\mathrm{NH}_{3}$ täglich produzierten. Bosch entwickelte die Technologie einer industriellen Hochdruckchemie mit ihren Öfen, Katalysatoren, Magnetklappen und weiteren Erfindungen. Das eine Produkt war der während der alliierten Seeblockade dringend benötigte Dünger, das andere das für die Herstellung von Explosivgeschossen begehrte Rohmaterial. Das Haber-Bosch-Verfahren sorgte für Brot und Granaten, ähnlich wie früher der Salpeter, dessen Verwendung für Schiesspulver mindestens so wichtig wie für Dünger war.

Haber, der als überzeugter Patriot den ersten Chlorgasangriff in Ypern ermöglichte, stand zeitweise auf einer Kriegsverbrecherliste. Zwar suchte er nicht nach dem Stein des Weisen, doch jahrelang vergeblich nach einem Verfahren, aus dem Meerwasser Gold zu gewinnen, was die Reparationsleistungen erleichtert hätte. Letztlich scheiterte der erfolgreiche Wissenschaftler am Rassenwahn der Nazis und starb mittellos und vereinsamt an einem Herzversagen in Basel. Bosch, Nobelpreisträger 1931, baute mit «IG Farben» in Leuna eine Riesenfabrik, die neben seinen Anlagen aus Flüssigkohle synthetischen Treibstoff herstellte. Er tat was er konnte, um seine jüdischen Mitarbeiter zu beschützen, doch um sein Lieblingsprojekt zu retten, war er zu einem Pakt mit dem Teufel bereit. Hitler misstraute ihm, und die Gestapo überwachte den liberalen, international gut vernetzten Freigeist. Boschs Situation wurde unhaltbar, er verfiel in Depressionen, wurde alkohol- und tablettensüchtig und verkroch sich so oft er konnte in seiner Villa, wo er seinen vielen Hobbys nachging und den Heidelberger Zoo plante und mitfinanzierte. Kurz vor seinem Tod im April 1940 prophezeite er seinem Sohn das Ende des dritten Reiches und die Zerstörung der Leuna-Werke aus der Luft. 1944 war es so weit, erstmals griffen 220 Bomber das strategisch wichtigste Ziel Deutschlands an. Leuna und andere Werke produzierten fast drei Viertel des von der Wehrmacht benötigten Treibstoffs, Spezialbenzin für die Luftwaffe, Explosivstoffe, Dünger und synthetischen Gummi.

Haber und Bosch vereinigen persönlich und beruflich alle Tragödien der Moderne. Sie waren rastlose Schaffer und geniale Erfinder zum Vorteil der Menschen wie zu deren Vernichtung. Die Haber-Bosch-Synthese bewahrt bis heute Millionen Menschen vor dem Verhungern und hat eine absehbare Katastrophe um Jahrzehnte hinausgezögert. Weltweit entfallen je nach Land 74-90\% des Mineraldüngers auf synthetischen Stickstoff. Der Energieverbrauch ist gross: Eine Tonne Ammoniak verbraucht zur Herstellung eine Tonne Erdgas. Gleichzeitig haben das übermässig eingesetzte Ammoniumnitrat und die Stickoxide der Verbrennungsmotoren die Luft, die Böden, das Grundwasser, Flüsse und Meere verseucht.

Eine Stickstoffwende ist nicht in Sicht. Noch mehr Dünger, Wasser und Pestizide für den ertragreicheren Weizen der grünen Revolution verstärken das Dilemma. Wir jagen nicht mehr mit Speer und Faustkeil. Die Speisekarten der Romantikstadt quellen über mit deftigen Fleischgerichten aus den vollgestopften Tierfabriken. 